(C) 1982. The Genetical Society of Great Britain

\title{
EVIDENCE FOR PREFERENTIAL MATING IN ADALIA BIPUNCTATA
}

\author{
MICHAEL MAJERUS, PETER O'DONALD and JACQUELINE WEIR \\ Department of Genetics, University of Cambridge, Downing Street, Cambridge CB2 3EH
}

Received 1.iii.82

\begin{abstract}
SUMMARY
Non-random mating may be involved in the maintenance of colour polymorphism in Adalia bipunctata. Mating choice experiments have been carried out on a stock of $\boldsymbol{A}$. bipunctata from Keele. Specific frequencies of the melanic quadrimaculata form and the non-melanic typica form were placed in population cages or mating chambers and allowed to mate. The frequencies of the forms amongst mating pairs were scored. The results gave a good fit to a model of mixed sexual selection and assortative mating showing a strongly frequency dependent, non-assorting preference for quadrimaculata males in the matings. Data from the wild Keele population showed a similar preference for quadrimaculata males, and an excess of males of a second melanic phenotype, sexpustulata. Observation of courting pairs indicated that female choice determined frequency of mating. Field data from Keele also gave evidence of assortative mating between typica and another non-melanic form, annulata.
\end{abstract}

\section{INTRODUCTION}

THE ladybird Adalia bipunctata $L$. is polymorphic for the colour and pattern of elytra and pronotum. There is a wide range of forms from all red to almost all black (Mader, 1926-37). The forms are controlled by a multiple allelic series comprising at least 11 alleles at a single locus. In general the more melanic forms are dominant to non-melanics (Lus, 1928, 1932). In England the commonest melanic forms are quadrimaculata and sexpustulata (black with four and six red spots respectively), and the most frequent non-melanics are typica (red with two round black spots) and a variable phenotype which is red with two irregular black patches or with two large black spots each having one or more small satellite spots. Following Lus (1928), this form will be referred to as annulata. There are a number of forms of $\boldsymbol{A}$. bipunctata which are non-melanic but have more black markings than typica. These include interpunctata, unifasciata, haneli, and annulata, which are all described by Lus (1928) as homozygous forms of the annulata allele $S^{a}$. The genetic relationships between these forms and other similar forms are not clearly understood, and in this paper they will all be classed together under the name annulata.

Mating pairs are often seen in the field. Lusis (1961) presented data showing that the frequency of melanics amongst mating pairs from Riga and Moscow was greater than in the populations from which they came. He suggested that this excess occurred because melanics have greater activity in sunlight. This he related to data recorded by Timofeeff-Ressovsky (1940) in Berlin. Here the frequency of melanics increased during the summer months. However, Creed (1975) found no excess of melanics in summed data from several British populations or from Potsdam (data quoted by Meissner, 1907a, $b, 1909)$. The method of analysis used by both 
Lusis and Creed is unsatisfactory for two reasons. Firstly, an excess of one morph in matings relative to the frequency of that morph in the population as a whole, combined with non-random mating among the mating imagines, could lead to apparent random mating. Secondly the method of analysis used is not valid because the expected values are calculated from samples which are themselves subject to sampling errors.

Muggleton (1979), using Meissner's data (1c) and data collected in 1976 and 1977 in England, suggested that non-random mating in $A$. bipunctata is frequency dependent, melanics being in excess when at a frequency of less than 40 per cent of the population, and typicals in excess when melanics comprise over 50 per cent of the population. O'Donald and Muggleton (1979) fitted this data to a model of constant and variable mating preference developed by O'Donald (1978). They found that the frequencies in Potsdam matings gave rise to strongly frequency dependent sexual selection, while the frequency dependence from the English data was less pronounced. However, the model used takes no account of the different phenotypes in the main data classes, melanics and non-melanics.

Karlin and O'Donald (1978) have developed a mixed assortative mating and sexual selection model for a dominant trait. This paper describes experimental and field data on the relative mating frequencies of the typica and quadrimaculata forms of $\boldsymbol{A}$. bipunctata and the fitting of these data to Karlin and O'Donald's model of sexual selection and assortative mating.

\section{Materials AND methods}

Adalia bipunctata is widely distributed over the temperate regions of the northern hemisphere. In Britain it is widely distributed and common. It hibernates as an imago. Generally, hibernating adults become active in late April or May. The ladybirds then mate and lay eggs in batches on herbage infected by aphids. Females lay on average approximately 250 eggs, but there is considerable variation and totals of over a thousand have been recorded (Weir, pers. obs.). Females mate several times. Hodek (1973) notes that one copulation is sufficient for permanent fertility of females in most species of ladybird. However, Ellingsen (1969) questions this for $A$. bipunctata because the death of males was correlated with a reduction in overall viability. Furthermore, if females are kept isolated from males after the first mating, the fertility of the later eggs is greatly reduced (Weir, pers. obs.). Sem'yanov (1970) has shown that copulation stimulates oviposition in $A$. bipunctata; the maximum number of eggs is laid after a female's first mating; oviposition then decreases but increases after each further mating.

The duration of the immature stages is variable, depending primarily on climate and food availability. It may be as little as 21 days in the laboratory, although five to eight weeks is probably usual in the wild in Britain. Muggleton (1978) suggests that in England A. bipunctata is univoltine. He noted that in southern and eastern England there was apparently only one generation in 1976, no mating pairs being observed after the end of June. However, Creed (1975) assumed that there were up to three generations a year in England. Furthermore matings have been noted during August in Surrey in 1975 and 1977, Staffordshire in 1981, and Cambridge in 1981 (Majerus, pers. obs.). If $A$. bipunctata is multivoltine 
in Britain the generations certainly overlap. Females will continue laying eggs for over three months during the summer, so that the hibernating populations may comprise imagines from two or more generations. In the wild both the larvae and adult ladybirds feed on various species of aphid, and adults will migrate from one plant species to another depending on aphid availability. They may be found on both herbaceous and arboreal species. They move to hibernation sites in late August and September.

The genetic relationships between some of the forms of $\boldsymbol{A}$. bipunctata were established by Lus $(1928,1932)$ by breeding laboratory stocks of discrete families for up to five generations. Of the forms discussed in this paper, he notes that there is a straightforward dominance hierarchy from the top dominant quadrimaculata through sexpustulata, and typica, to annulata, the bottom recessive.

Hodek (1973) notes that inbreeding causes a very rapid decline in viability; this is because $A$. bipunctata has a number of recessive alleles which are lethal when homozygous and the frequency of these is high in all populations (Lusis, 1947a, $b$ ).

The stock being considered in this paper originally came from a population in the grounds of Keele University, Staffordshire (grid ref: SJ823441). Two samples of ladybirds comprising four phenotypes, quadrimaculata, sexpustulata, typica and annulata, were collected in May 1981.

The main stock was reared in population cages in a glasshouse. The cages were $2 \mathrm{~m} \times 1 \mathrm{~m} \times 1 \mathrm{~m}$ in size. They were constructed of perspex and supported by a dexion frame with wood and muslin doors at each end. Each cage contained four trays of sand in which six $125 \mathrm{~mm}$ pots of broad beans (Vicia faba $L$.) were growing, six plants per pot. The trays of beans were changed by rotation, the oldest tray being substituted by a new tray of two-week-old beans each week. Fresh beans were infected with the aphid Acyrthosiphon pisum Harris. When necessary supplementary heat and light were used to ensure a minimum temperature of $21.1^{\circ} \mathrm{C}$ and 16 hours light.

This stock has been used for two types of experiment to investigate mating preferences between phenotypes; population cage experiments and formal mating tests. Data were also collected from the Keele population in August 1981.

\section{(i) Population cage experiments}

Populations of 100 ladybirds of specific phenotypes were set up in the population cages and maintained as outlined above. Two phenotypes, quadrimaculata and typica were used. Three phenotypic ratios were used in separate experiments: 30 quadrimaculata, 70 typica; 50 quadrimaculata, 50 typica; 70 quadrimaculata, 30 typica. Two experiments were conducted at each ratio. In each population there were equal numbers of males and females. It is difficult to differentiate the sexes of $A$. bipunctata by sight. Males are generally smaller than females and have a more rounded abdomen; however, these characters are not absolutely reliable. Despite this we have found that with practice we can attain an accuracy exceeding 96 per cent when determining the sexes of our laboratory stocks, and 98 per cent when sexing ladybirds in the field where they seem to vary less in size. 
The phenotypes in copuli were recorded by direct observation every hour. The duration of each experiment varied slightly; the end of each experiment being determined by the emergence of the first progeny which occurred generally about four weeks after the beginning of the experiment.

\section{(ii) Formal mating tests}

A sample of ladybirds was removed from the main stock. The sex of each individual was determined and males and females were kept separate for at least 48 hours prior to a test. Females laying eggs during this period were returned to the main stock. The procedure of keeping the sexes separate would also allow males which had recently mated to recover their normal levels of sexual activity. Equal numbers of males and females of each phenotype (quadrimaculata and typica) were introduced into a mating chamber. When matings occurred, pairs were removed from the chamber and replaced by a male and female of the same phenotype. The tests lasted approximately eight hours or until the replacement stocks had been exhausted. The phenotypes of the mating pairs were recorded.

\section{(iii) Keele population field data}

Data on mating preferences in the wild Keele population were collected to compare with the results of the population cage experiments and formal mating tests. To assess the frequency in the population as a whole, samples of mating and non-mating ladybirds were recorded during 3-5 August 1981, both the phenotype and sex of each individual being noted.

\section{Results}

\section{(i) Population cage experiments}

The data from the population cage experiments are given in table 1(i). Comparisons of the data from each pair of experiments at a particular frequency showed no significant heterogeneity. Chi-squared tests, the results of which are given in table 1 (ii), showed significant deviations of the observed matings from the expectations based on the frequencies of the phenotypes used in the experiments. Analysis of chi-squared demonstrated that this was due to a significant excess of quadrimaculata males in all the experiments. This analysis also showed that there was no significant deviation from expected values amongst mating females, nor was the residual chi-squared, which is partly dependent upon assortment in the matings, significant. Direct tests of the significance of assortment, using a cross product ratio, also gave non-significant results at all frequencies.

Karlin and O'Donald (1978) described a model which combined both assorting and non-assorting preferences for two phenotypes. O'Donald (1980) fitted this model to data of matings of two mutant strains of the parasitic wasp Mormoniella vitripennis. The same method can be used to fit the model to the population cage data of the typica $(\mathrm{T})$ and quadrimaculata $(\mathrm{Q})$ ladybirds. Consider the two phenotypes $\mathrm{T}$ and $\mathrm{Q}$ at frequencies $u$ and $v$ in males and females. The following parameters describe the 
TABLE 1

(i) The phenotypes of mating pairs in the population cage experiments ( $Q=$ quadrimaculata, $T=$ typica)

\begin{tabular}{|c|c|c|c|c|c|c|}
\hline $\begin{array}{l}\text { Experiment } \\
\text { number }\end{array}$ & $\begin{array}{l}\text { Number of } \\
\text { Ladybirds }\end{array}$ & $Q \times Q$ & $\begin{array}{c}\text { Matings } \\
\mathrm{Q} \times \mathrm{T}\end{array}$ & $\begin{array}{c}\text { Observed } \\
\mathbf{T} \times \mathbf{Q}\end{array}$ & $\begin{array}{c}\text { (Males first) } \\
\mathrm{T} \times \mathrm{T}\end{array}$ & Total \\
\hline 5 & $30 \mathrm{Q}, 70 \mathrm{~T}$ & 13 & 21 & 12 & 27 & 73 \\
\hline 12 & $30 \mathrm{Q}, 70 \mathrm{~T}$ & 16 & 27 & 14 & 34 & 91 \\
\hline 9 & $50 \mathrm{Q}, 50 \mathrm{~T}$ & 24 & 20 & 9 & 9 & 62 \\
\hline 10 & $50 \mathrm{Q}, 50 \mathrm{~T}$ & 18 & 13 & 7 & 7 & 45 \\
\hline 8 & $70 \mathrm{Q}, 30 \mathrm{~T}$ & 71 & 24 & 15 & 8 & 118 \\
\hline 11 & $700,30 \mathrm{~T}$ & 60 & 27 & 12 & 7 & 106 \\
\hline
\end{tabular}

(ii) Analysis of chi-squared

\begin{tabular}{|c|c|c|c|c|}
\hline $\begin{array}{c}\text { Component of } \\
\text { variation }\end{array}$ & $30 \mathrm{Q}: 70 \mathrm{~T}$ & $50 \mathrm{Q}: 50 \mathrm{~T}$ & $70 \mathrm{Q}: 30 \mathrm{~T}$ & Dfs \\
\hline $\begin{array}{l}\text { Deviation in males } \\
\text { Deviation in females } \\
\text { Residugl }\end{array}$ & $\begin{array}{r}22.4402 \\
0.9767 \\
2.3928\end{array}$ & $\begin{array}{r}17.2804 \\
0.7570 \\
0.7570\end{array}$ & $\begin{array}{r}13 \cdot 5000 \\
0.0306 \\
0.7711\end{array}$ & $\begin{array}{l}1 \\
1 \\
1\end{array}$ \\
\hline Total & $25 \cdot 8097$ & $18 \cdot 7944$ & $14 \cdot 3017$ & 3 \\
\hline
\end{tabular}

"Dfs" refers to degrees of freedom for the tests of each pair of experiments at a given ratio of $Q: T$.

preferential mating:

\title{
Preference for $\mathrm{T} \quad$ Preference for $\mathrm{Q}$
}

\author{
Non-assorting \\ preference \\ Assorting \\ preference
}

$\begin{array}{ll}\alpha & \gamma \\ a & c\end{array}$

Preferential matings thus take place at the following frequencies:

$\begin{array}{ccc} & \text { Male T } & \text { Male Q } \\ \text { Female T } & u(\alpha+a) & \gamma u \\ \text { Female Q } & \alpha v & v(\gamma+c)\end{array}$

Since $\mathrm{T}$ and $\mathrm{Q}$ females mate at random with frequencies $u(1-\alpha-\gamma-a)$ and $v(1-\alpha-\gamma-c)$, the total frequencies of the matings, preferential and random, will then be:

$$
\begin{aligned}
& P_{T}(\mathrm{~T} \times \mathrm{T})=u(\alpha+a)+u^{2}(1-\alpha-\gamma-a) \\
& P_{T}(\mathrm{~T} \times \mathrm{Q})=\gamma u+u v(1-\alpha-\gamma-a) \\
& P_{T}(\mathrm{Q} \times \mathrm{T})=\alpha v+u v(1-\alpha-\gamma-c) \\
& P_{T}(\mathrm{Q} \times \mathrm{Q})=v(\gamma+c)+v^{2}(1-\alpha-\gamma-c)
\end{aligned}
$$

When multiplied by the total number of matings observed at each ratio of males, these expressions then give the expectations of the numbers of matings observed. If, at a particular male ratio, the observed numbers are $N(\mathrm{TT}), N(\mathrm{TQ}), N(\mathrm{QT})$ and $N(\mathrm{QQ})$, then the $\log$ likelihood is given by the 
equation

$$
\begin{aligned}
\log L= & N(\mathrm{TT}) \log P_{T}(\mathrm{TT})+N(\mathrm{TQ}) \log P_{T}(\mathrm{TQ}) \\
& +N(\mathrm{QT}) \log P_{T}(\mathrm{QT})+N(\mathrm{QQ}) \log P_{T}(\mathrm{QQ})
\end{aligned}
$$

where the summation is taken over each of the different experiments. The method of trial and error, described by O'Donald (1980, pp. 72-77) has been used to find the maximum likelihood estimates of the parameters. The expected numbers of the matings at maximum likelihood, corresponding to the observed numbers in table 1(i), were calculated from the values of $P_{T}(\mathrm{TT}), P_{T}(\mathrm{TQ}), P_{T}(\mathrm{QT})$ and $P_{T}(\mathrm{QQ})$, and hence the residual chisquared after the fitting of the model. There are four classes of matings and three degrees of freedom after the total number of matings at each male ratio has been allowed for-nine degrees of freedom before any parameters have been fitted.

Table 2 gives the estimates of the parameters and analysis of chisquared.

\section{TABLE 2}

Fitting data of matings of quadrimaculata and typica, from the population cage experiments,

\begin{tabular}{|c|c|c|c|c|c|c|}
\hline \multirow[t]{2}{*}{ Parameters } & \multicolumn{4}{|c|}{ M.L. estimates of parameters } & \multirow[t]{2}{*}{ Residual } & \multirow[t]{2}{*}{ Dfs } \\
\hline & $\hat{\alpha}$ & $\hat{\gamma}$ & $\hat{a}$ & $\hat{c}$ & & \\
\hline - & - & - & - & - & 58.9059 & 9 \\
\hline$\alpha$ & 0.0000 & - & - & - & 58.9060 & 8 \\
\hline$\gamma$ & - & 0.3046 & - & - & $7 \cdot 0408$ & 8 \\
\hline$a$ & - & - & 0.0000 & - & 58.9059 & 8 \\
\hline$c$ & - & - & - & 0.3924 & $19 \cdot 4449$ & 8 \\
\hline$\alpha, \gamma$ & 0.0000 & $0 \cdot 3050$ & - & - & 7.0403 & 7 \\
\hline$\alpha, a$ & 0.0000 & - & 0.0000 & - & 58.9059 & 7 \\
\hline$\alpha, c$ & 0.0000 & - & - & $0 \cdot 3939$ & $19 \cdot 4481$ & 7 \\
\hline$\gamma, a$ & - & 0.3323 & 0.0677 & - & $6 \cdot 1983$ & 7 \\
\hline$\gamma, c$ & - & 0.2304 & - & $0 \cdot 1619$ & 3.5310 & 7 \\
\hline$a, c$ & - & - & 0.0000 & $0 \cdot 3913$ & $19 \cdot 4435$ & 7 \\
\hline$\alpha, \gamma, a$ & 0.0000 & $0 \cdot 3335$ & 0.0694 & - & $6 \cdot 1976$ & 6 \\
\hline$\alpha, \gamma, c$ & 0.0000 & $0 \cdot 2300$ & - & $0 \cdot 1627$ & 3.5315 & 6 \\
\hline$\alpha, a, c$ & 0.0000 & - & 0.0000 & 0.3921 & $19 \cdot 4445$ & 6 \\
\hline$\gamma, a, c$ & - & 0.2304 & 0.0000 & $0 \cdot 1620$ & $3 \cdot 5309$ & 6 \\
\hline$\alpha, \gamma, a, c$ & 0.0000 & 0.2312 & 0.0000 & 0.1597 & 3.5297 & 5 \\
\hline
\end{tabular}
to Karlin and O'Donald's model of sexual selection and assortative mating

Only $\gamma$ and $c$ remove significant variation, with maximum likelihood (M.L.) estimates

$$
\begin{aligned}
& \hat{\gamma}=0.2304 \\
& \hat{c}=0.1619 .
\end{aligned}
$$

The results show that the assorting parameter $c$ is not sufficient to provide a fit of the model for it leaves a significant chi-squared with 
$p=0.0127$. However, the non-assorting parameter $\gamma$ is sufficient to provide a fit of the model, for it leaves a non-significant chi-squared with $p=0.532$. If $c$ is then fitted in addition to $\gamma$, the residual chi-squared is further reduced by 3.5098 . This is an almost significant reduction, with $P=0.0610$. After fitting $\gamma$

$$
\log _{e} L=-603 \cdot 335 \text {. }
$$

Then after fitting $c$ as well

$$
\log _{e} L=-601 \cdot 524 \text {. }
$$

So the extra parameter $c$ has increased the log likelihood by 1.811 . This is nearly, but not quite, a significant increase in log likelihood. So we conclude that the parameter $\gamma$ is sufficient to fit the data with M.L. estimate

$$
\hat{\gamma}=0.3046 \text {. }
$$

(ii) Formal mating tests

The results of the formal mating tests are given in table 3. The data show a significant deviation from expected. Analysis of chi-squared demonstrates this deviation to be due to a significant excess of quadrimaculata males in matings. Again there is no deviation from expected numbers of mating females, nor any significant assortment.

TABLE 3

Matings observed in formal mating tests using equal numbers of quadrimaculata

$(Q)$ and typica $(T)$ (male phenotype given first)

$\begin{array}{ccccc}\mathrm{Q} \times \mathrm{Q} & \mathrm{Q} \times \mathrm{T} & \mathrm{T} \times \mathrm{Q} & \mathrm{T} \times \mathrm{T} & \text { Total } \\ 47 & 39 & 26 & 28 & 140\end{array}$

Analysis of chi-squared Component of Variation

Deviation from $1: 1$ in males

Deviation from $1: 1$ in females

Assortment

\begin{tabular}{cc} 
Value of chi-squared & Dfs \\
$7 \cdot 3143$ & 1 \\
$0 \cdot 2571$ & 1 \\
0.7143 & 1 \\
\hline $8 \cdot 2857$ & - \\
\hline
\end{tabular}

The preference for quadrimaculata is easily estimated. The phenotypes were maintained with equal numbers of unmated quadrimaculata and typica males and females. If a proportion of $\gamma$ females of each phenotype prefer quadrimaculata males, the matings should take place at frequencies

and

$$
\gamma+\frac{1}{2}(1-\gamma)=\frac{1}{2}+\frac{1}{2} \gamma \text { for quadrimaculata }
$$

$$
\frac{1}{2}-\frac{1}{2} \gamma \text { for typica. }
$$

If $n_{Q}$ and $n_{T}$ are the numbers of these matings, the maximum likelihood estimate of $\gamma$ is given by

$$
\begin{aligned}
\hat{\gamma} & =\frac{n_{Q}-n_{T}}{n_{Q}+n_{T}} \\
& =0.229 .
\end{aligned}
$$


This estimate has variance

Thus

$$
\begin{aligned}
\operatorname{var}(\hat{\gamma}) & =\frac{1-\gamma^{2}}{n_{Q}+n_{T}} \\
& =0.00677
\end{aligned}
$$

$$
\hat{\gamma} \pm \text { S.E. }(\hat{\gamma})=0 \cdot 229 \pm 0 \cdot 082
$$

We may compare the estimates of the preference for quadrimaculata obtained from the results of each of the population cage experiments. In general if quadrimaculata is at a frequency $v$, the maximum likelihood estimate of the preference $\gamma$ is given by

where $n=n_{Q}+n_{T}$.

$$
\gamma=\frac{n_{Q}(1-v)-n_{T} v}{n(1-v)}
$$

This estimate has the variance

$$
\operatorname{var}(\hat{\gamma})=\frac{(1-\gamma)(v+\gamma-\gamma v)}{n(1-v)}
$$

Thus we obtain the following estimates with their standard errors.

(a) Cage experiments at $30 \mathrm{Q}: 70 \mathrm{~T}$

$$
\hat{\gamma}=0 \cdot 2422 \pm 0 \cdot 0557 \text {. }
$$

(b) Cage experiments at 50 Q:50 T

$$
\hat{\gamma}=0 \cdot 4019 \pm 0 \cdot 0885 \text {. }
$$

(c) Cage experiments at $70 \mathrm{Q}: 30 \mathrm{~T}$

$$
\hat{\gamma}=0 \cdot 3750 \pm 0 \cdot 0869 \text {. }
$$

The weighted mean of these estimates is

$$
\begin{aligned}
\bar{\gamma} & =\frac{\sum \hat{\gamma} / \operatorname{var}(\hat{\gamma})}{\sum 1 / \operatorname{var}(\hat{\gamma})} \\
& =0.3073 .
\end{aligned}
$$

This is very close to the overall maximum likelihood estimate of $\gamma$. The weighted mean of estimates for all population cage experiments and the formal mating tests is found to be

$$
\overline{\bar{\gamma}}=0 \cdot 2914 \text {. }
$$

The heterogeneity in the four estimates is tested by

$$
\begin{aligned}
\chi_{3}^{2} & =\sum(\hat{\gamma}-\bar{\gamma})^{2} / \operatorname{var}(\hat{\gamma}) \\
& =3.8475 \\
P & =0.278 .
\end{aligned}
$$

\section{(iii) Keele population data}

The data collected from the Keele population are presented in table 4(i), which gives the phenotypes of all the ladybirds sampled, including 
TABLE 4

(i) The phenotypes of A. bipunctata sampled at Keele, August 1981 (including mating pairs)

$\begin{array}{lcccccc} & \text { sub. } & \text { quad. } & \text { sexp. } & \text { typ. } & \text { ann. } & \text { Totals } \\ \text { Males } & 1 & 123 & 19 & 204 & 100 & 447 \\ \text { Females } & 3 & 111 & 14 & 197 & 84 & 409\end{array}$

(ii) The phenotypes of mating pairs of A. bipunctata at Keele, August 1982

\begin{tabular}{lccrrc} 
& \multicolumn{5}{c}{ Females } \\
Males & quad. & sexp. & typ. & ann. & Totals \\
quad. & 19 & 2 & 31 & 14 & 66 \\
sexp. & 3 & 1 & 6 & 2 & 12 \\
typ. & 20 & 2 & 28 & 8 & 58 \\
ann. & 11 & 1 & 9 & 12 & 33 \\
Totals & 53 & 6 & 74 & 36 & 169
\end{tabular}

sub. is sublunata.

quad. in quadrimaculata.

sexp. is sexpustulata.

typ. is typica.

ann. in annulata.

mating pairs, and table 4(ii), which gives the phenotypes of mating ladybirds. The frequencies of the phenotypes in mating pairs were compared with those in the non-mating sample, using a Brandt and Snedecor partitioned contingency chi-squared test, presented in table 5 . As in the population cage experiments and formal mating tests, quadrimaculata males mate in excess of their frequency in the population. Sexpustulata males show a

TABLE 5

Comparison of mating and non-mating A. bipunctata from the Keele sample, August 1981

\begin{tabular}{|c|c|c|c|c|c|}
\hline Males & mating & non-mating & Total & $\begin{array}{l}\text { Value of } \\
\text { chi-squared }\end{array}$ & Dfs \\
\hline $\begin{array}{l}\text { typ. } \\
\text { ann. }\end{array}$ & $\begin{array}{l}58 \\
33\end{array}$ & $\begin{array}{r}146 \\
67\end{array}$ & $\begin{array}{l}204 \\
100\end{array}$ & 0.5957 & 1 \\
\hline $\begin{array}{l}\mathrm{Nm} \\
\text { sexp. }\end{array}$ & $\begin{array}{l}91 \\
12\end{array}$ & $\begin{array}{r}213 \\
7\end{array}$ & $\begin{array}{r}304 \\
19\end{array}$ & $8 \cdot 3947$ & 1 \\
\hline $\begin{array}{l}\mathrm{Nm}+\text { sexp. } \\
\text { quad. }\end{array}$ & $\begin{array}{r}103 \\
66\end{array}$ & $\begin{array}{r}220 \\
58\end{array}$ & $\begin{array}{l}323 \\
124\end{array}$ & $17 \cdot 3491$ & 1 \\
\hline $\begin{array}{l}\text { Grand Total } \\
\text { Continge }\end{array}$ & \multicolumn{5}{|c|}{ Contingency $\chi_{3}^{2}=26 \cdot 3395$} \\
\hline \multicolumn{6}{|l|}{ Females } \\
\hline $\begin{array}{l}\text { typ. } \\
\text { ann. }\end{array}$ & $\begin{array}{l}74 \\
36\end{array}$ & $\begin{array}{r}123 \\
48\end{array}$ & $\begin{array}{r}197 \\
84\end{array}$ & 0.6806 & 1 \\
\hline $\begin{array}{l}\mathrm{Nm} \\
\text { sexp. }\end{array}$ & $\begin{array}{r}110 \\
6\end{array}$ & $\begin{array}{r}171 \\
8\end{array}$ & $\begin{array}{r}281 \\
14\end{array}$ & 0.0758 & 1 \\
\hline $\begin{array}{l}\mathrm{Nm}+\text { sexp. } \\
\text { quad. }\end{array}$ & $\begin{array}{r}116 \\
53\end{array}$ & $\begin{array}{r}179 \\
61\end{array}$ & $\begin{array}{l}295 \\
114\end{array}$ & 1.7430 & 1 \\
\hline Grand Total & 169 & 240 & 409 & & \\
\hline
\end{tabular}

$\mathrm{Nm}$ represents both typica and annulata 
similar excess in their relative mating frequency. But there is no significant difference in the numbers of mating and non-mating typica males when compared with annulata males, nor do any of the female phenotypes differ in relative frequency of mating.

The mating data were analysed using Kimball's formulae (1954) for chi-squared. These formulae give a strictly orthogonal and additive analysis of chi-squared. The standard formula for the $2 \times 2$ contingency table gives closely similar, but not exactly additive values. For the analysis of the mating data, the two melanic forms, quadrimaculata and sexpustulata, have been classed together. Only mating pairs have been used in the analysis, which compares the relative frequencies of matings among different classifications of the phenotypes. For example, when the numbers of typica and annulata females are compared to the typica and annulata males they

\section{TABLE 6}

Analysis of chi-squared of data on matings of A. bipunctata sample from Keele, August 1981

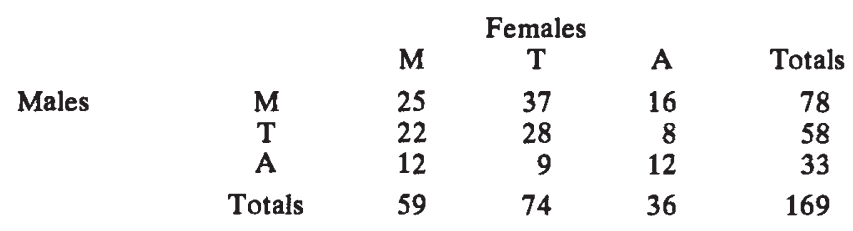

(i) Difference in preference of $T$ and $A$ females for $T$ and $A$ males

\begin{tabular}{lrrrr} 
& \multicolumn{5}{c}{ Females } \\
Males & T & 28 & A & \\
& A & 9 & 12 & $\chi_{1}^{2}=7 \cdot 1410$
\end{tabular}

(ii) Difference in preference of $M$ and $N m$ females for $T$ and $A$ males

\begin{tabular}{lcccc} 
& \multicolumn{5}{c}{ Females } \\
Males & M & Nm & \\
& T & 22 & 36 & $\chi_{1}^{2}=0.0227$
\end{tabular}

(iii) Difference in preference of $T$ and $A$ females for $M$ and $N m$ males

\begin{tabular}{lcccc} 
& \multicolumn{4}{c}{ Females } \\
Males & T & A & \\
& M & 37 & 16 & \\
& Nm & 37 & 20 & $\chi_{1}^{2}=0.3008$
\end{tabular}

(iv) Difference in preference of $M$ and $N m$ females for $M$ and $N m$ males

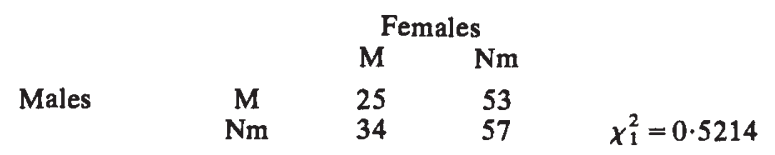

Overall contingency $\chi_{3}^{2}=7.9859$

$\mathrm{T}$ represents typica.

A represents annulata.

M represents quadrimaculata and sexpustulata.

$\mathrm{Nm}$ represents typica and annulata. 
mated with, the only effect tested is the possible assortment or disassortment between typica and annulata. The analysis is presented in table 6. Since the frequencies of mating individuals are not being compared with the frequencies of non-mating individuals, only an assortative mating preference, not an overall mating advantage, can be detected. The analysis shows that there is a significant difference in the preference of typica and annulata females for typica and annulata males. Observation shows that this difference in the preference arises because the two phenotypes mate assortatively. The other components of the chi-squared show no assortative mating.

\section{Discussion}

The population cage experiments and the formal mating tests show that quadrimaculata males mate more often than the typica males. This mating advantage is most probably determined by female preference. In the population cage experiments, a parameter of a non-assorting preference for quadrimaculata is sufficient to provide a full fit of the data to the model with the estimate $\hat{\gamma}=0 \cdot 3046$. This excellent fit of a model of female preference is obtained with the same estimate of preference at all three different sets of frequencies of quadrimaculata and typica. This level of preferential mating gives rise to precisely the level of frequency dependent advantage gained by quadrimaculata males. According to the model, at a frequency of 0.3 , quadrimaculata males mate with 1.71 females compared to an overall average of one female for each male. At a frequency of 0.5 , quadrimaculata males mate with 1.30 females. At a frequency of 0.7 , quadrimaculata males mate with 1.13 females. The actual number of matings of quadrimaculata males per female were as follows: at a frequency of $0.3,1.57$ matings; at a frequency of $0.5,1.4$ matings; and at a frequency of $0.7,1.16$ matings. Thus the great frequency dependent advantage that quadrimaculata males gain at lower frequencies is close to that expected in the model of preferential mating. Models of male competition do not produce strong frequency dependence in the mating advantage of the males (O'Donald, 1980). Male competition can produce a frequency dependent advantage if one male phenotype is likely to displace copulating males of another phenotype. But, no such displacement has been observed in the matings in either the laboratory or the field. Indeed only rarely were two males seen in attendance on a female at one time. Females, however, were frequently seen to reject males. The mechanism of sexual selection thus appears to be female choice. Females reject quadrimaculata males less often than typica males.

The hypothesis of preferential mating by female choice is supported by the strong frequency dependent advantage gained by quadrimaculata males at the lower frequencies. This frequency dependent advantage is exactly what a model of female choice predicts. The frequency of melanics in the Keele population is 31.66 per cent. The results presented are therefore consistent with the general finding of Muggleton (1978) that there is an excess of melanics amongst mating pairs compared with their frequency in the population as a whole when melanics comprise less than 40 per cent of the population. However, this does not mean that we would expect to find preferences for quadrimaculata males in all populations where quadrimaculata males constitute less than 40 per cent of the population. 
If female preference is genetically controlled, the level of preference will presumably differ in different populations in the same way as we should expect frequencies of alleles, which control any polymorphism, to vary. Models of the evolution of preference show that a gene giving rise to preference for a specific phenotype can not be selected to reach fixation in a population (O'Donald 1980). Therefore, if female preferences are genetically determined we should expect to find a polymorphism in their preferences: some females will show the preference and some will not. The level attained in any population will depend on several factors such as the frequency at which the genes for the preference were introduced into the population, as well as the frequency of the gene for the preferred phenotype. Consequently different populations may vary widely in the level of preference attained.

Acknowledgments. - We are very grateful to Mr Dennis Parkinson, Mr Alan Feast and Mr Roger Ison for their invaluable assistance and to Mrs June Hunt for typing the manuscript. We are greatly indebted to the Science Research Council (Grant number GR/B30807) for their financial support.

\section{REFERENCES}

CREED, E. R. 1975. Melanism in the two-spot ladybird: the nature and intensity of selection. Proc. R. Soc. Lond. B, 190, 135-148.

ELLINGSEN, I. J. 1969. Fecundity, Aphid consumption and survival of the aphid predator Adalia bipunctata L. (Col., Coccinellidae). Norsk. ent. Tiddsskr., 16, 91-95.

HODEK. I. 1973. Biology of Coccinellidae. Academia, Prague.

KARLIN, S., AND O'DONALD, P. 1978. Some population genetic models combining sexual selection with assortative mating. Heredity, 41, 165-174.

KIMBALL, A. W. 1954. Short-cut formulas for the exact partition of $\chi^{2}$ in contingency tables. Biometrics, 10, 452-458.

LUS, J. J. (LUSIS), 1928. On inheritance of colour and pattern in ladybeetles Adalia bipunctata and Adalia decimpunctata. Izv. Byuro. Genet. Leningrad. 6, 89-163.

LUS, J. J. (LUSIS). 1932. An analysis of the dominance phenomenon in the inheritance of the elytra and pronotum colour in Adalia bipunctata. Trudy Lab. Genet., 9, 135-162.

LUS, J. J. (LUSIS). 1947a. Some aspects of the population increase in Adalia bipunctata. 1. Heterozygosity of populations in lethal alleles. Dokl. Akad. Nauk. SSSR, 57, 825-828.

LUS, J. J. (LUSIS), $1947 \mathrm{~b}$. Some aspects of the population increase in Adalia bipunctata. 2. The strains without males. Dokl. Akad. Nauk. SSSR, 57, 951-954.

LUSIS, J. J. 1961. On the biological meaning of colour polymorphism of ladybeetle Adalia bipunctata L. Latv. Ent., 4, 329.

MADER, L. 1926-1937. Evidenz der palaearktischen Coccinelliden und ihrer Aberationen in Wort und Bild. Vienna.

MEISSNER, O. 1907a. Die relative Häufigkeit der Varietäten von Adalia bipunctata L. in Potsdam (1906). Z. wiss. Insekt Biol., 3, 12-20, 39-45.

MEISSNER, O. 1907 b. Die relative Häufigkeit der Varietäten von Adalia bipunctata L. in Potsdam (1907) Z. wiss. Insekt Biol., 3, 309-313, 334-344, 369-374.

MEISSNER, O. 1909. Die relative Häufigkeit der Varietaten von Adalia bipunctata L. in Potsdam (1908). Z. wiss. Insekt Biol., 5, 231-242.

MUGGLETON, J. 1978. Selection against the melanic morphs of Adalia bipunctata (two-spot ladybird): a review and some new data. Heredity, 40, 269-280.

MUGGleTON, J. 1979. Non-random mating in wild populations of polymorphic Adalia bipunctata. Heredity, 42, 57-65.

O'DONALD, P. 1978. Theoretical aspects of sexual selection: a generalized model of mating behaviour. Theor. Pop. Biol., 13, 226-243.

O'DONALD, P., AND MUGGLETON, J. 1979. Melanic polymorphism in ladybirds maintained by sexual selection. Heredity, 43, 143-148. 
O'DONAld, P. 1980. Genetic Models of Sexual Selection. Cambridge University Press.

SEM'YANOV, V. P. 1970. Biological properties of Adalia bipunctata (Coleoptera: Coccinellidae) in conditions of Leningrad region. Zashch. Rast. Vredit. Bolez., 127, 105-112.

TIMOFEEFF-RESSOVSKY, N. W. 1940. Zur Analyse des Polymorphismus bei Adalia bipunctata L. Biol. Zbl., 60, 130-137. 